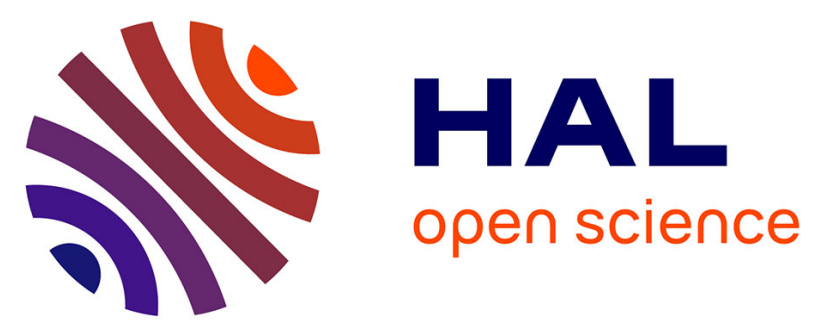

\title{
Comparative study on volatile compounds, fatty acids, squalene and quality parameters from whole fruit, pulp and seed oils of two tunisian olive cultivars using chemometrics
}

Amir Ben Mansour, Guido Flamini, Zied Ben Selma, Yveline Le Dréau, Jacques Artaud, Ridha Abdelhedi, Mohamed Bouaziz

\section{To cite this version:}

Amir Ben Mansour, Guido Flamini, Zied Ben Selma, Yveline Le Dréau, Jacques Artaud, et al.. Comparative study on volatile compounds, fatty acids, squalene and quality parameters from whole fruit, pulp and seed oils of two tunisian olive cultivars using chemometrics. European Journal of Lipid Science and Technology, 2015, 117 (7), pp.976-987. 10.1002/ejlt.201400159 . hal-03542895

\section{HAL Id: hal-03542895 https://hal.science/hal-03542895}

Submitted on 25 Jan 2022

HAL is a multi-disciplinary open access archive for the deposit and dissemination of scientific research documents, whether they are published or not. The documents may come from teaching and research institutions in France or abroad, or from public or private research centers.
L'archive ouverte pluridisciplinaire HAL, est destinée au dépôt et à la diffusion de documents scientifiques de niveau recherche, publiés ou non, émanant des établissements d'enseignement et de recherche français ou étrangers, des laboratoires publics ou privés. 


\title{
Comparative study on volatile compounds, fatty acids, squalene and quality parameters from whole fruit, pulp and seed oils of two tunisian olive cultivars using chemometrics.
}

\author{
Ridha Abdelhedi ${ }^{1}$ and Mohamed Bouaziz ${ }^{1,5}$ \\ ${ }^{1}$ Laboratoire d'Electrochimie et Environnement, Université de Sfax, Sfax, Tunisie \\ ${ }^{2}$ Dipartimento di Farmacia, Pisa, Italy \\ ${ }^{3}$ Laboratoire Nature Orient, Sousse, Tunisie \\ ${ }^{4}$ Aix-Marseille Université, LISa, Equipe METICA, France \\ ${ }^{5}$ Institut Supérieur de Biotechnologie de Sfax, Université de Sfax, Sfax, Tunisie
}

Amir Ben Mansour ${ }^{1}$, Guido Flamini ${ }^{2}$, Zied Ben Selma ${ }^{3}$, Yeveline Le Dréau ${ }^{4}$, Jacques Artaud ${ }^{4}$,

The oils of olive fruits, pulps and seeds from main Tunisian cultivars of olive trees (Chemlali and Oueslati) were extracted at two different indices of maturity. The free acidity, peroxide value, spectrophotometric indices, chlorophyll content, squalene, fatty acids, aroma, and sensory profiles of the oils were analyzed. Fruit and pulp oils are similar in fatty acid compositions, while seed oils have fatty acid profiles that are different from both varieties. For the first time in this work, squalene content in the fruit, pulp, and seed oils was measured by gas chromatography and was found to decrease during maturation. Squalene concentration in the seed oils was lower than that found in fruit and pulp oils. The volatile profiles of twelve Tunisian olive oils obtained from different parts of the fruit were established by solid phase micro-extraction (SPME) coupled with gas chromatography (GC) and gas chromatography-mass spectrometry (GC-MS). Sixty-six compounds were identified and characterized, representing 92.4 and $97.6 \%$ of the total volatiles. Principal component analysis showed that olive oil quality is strongly affected by olive cultivar, maturity index and the different olive parts.

Practical applications: Nowadays, olive oil extraction processes require grinding of whole olives. The proposed method is a useful alternative process for olive oil production that involves olive destoning before extraction of the oil. Although destoning lowers olive oil yields, manufacturing plants for stone removal and milling of pulp have been recently set up, showing good oil yield. Interest in this technology is increasing, and some producers believe that oils obtained from destoned olives are of better quality than oils extracted from the whole fruit. Indeed, oils extracted from destoned olives have better sensory properties than oils obtained from the traditional milling of entire fruits, which is very important from a marketing point of view for olive oil companies.

Keywords: Olive oil / Chemlali and Oueslati cultivars / Olive fruit parts / Volatile compounds / SPME / Chemometrics

\footnotetext{
Correspondence: Pr. Mohamed Bouaziz, Laboratoire d'Electrochimie et Environnement, Institut Supérieur de Biotechnologie de Sfax, BP: 1175 3038, Université de Sfax, Tunisie.

E-mail: mohamed.bouaziz@fsg.rnu.tn

Fax: +21674674364
}

Abbreviations: $\mathbf{C H}$, chemlali; OU, oueslati; MI, maturation index; ADH, alcohol dehydrogenase enzyme; $\mathbf{C l}$, chemical ionization; VOO, virgin olive oil; FaMEs, fatty acid methyl esters; GC, gas chromatography; GC-CI-MS, gas chromatography with chemical ionization mass spectrometry; IOOC,
International Olive Oil Council; LOX, lipoxygenase enzyme; LRI, linear retention indices; MS, mass spectrometry; MUFA, mono-unsaturated fatty acids; PCA, principal compounds analysis; PV, peroxide value; SD, standard deviation; SFA, saturated fatty acids; SPME, solid-phase microextraction. FC1 whole fruit oil, $\mathrm{MI}=1$; $\mathbf{F C 2}$, whole fruit oil, $\mathrm{MI}=$ 5.42; PC1, pulp oil, $\mathrm{MI}=1$; $\mathbf{P C 2}$, pulp oil, $\mathrm{MI}=5.42$; $\mathbf{S C 1}$, seed oil, $\mathrm{MI}=1$; SC2, seed oil, MI = 5.42; FO1, whole fruit oil, MI=1; FO2, whole fruit oil, $\mathrm{MI}=5.23$; PO1, pulp oil, $\mathrm{MI}=1$; PO2, pulp oil, $\mathrm{MI}=5.23$; SO1, seed oil, $\mathrm{MI}=1$; SO2, seed oil, $\mathrm{MI}=5.23$ 


\section{Introduction}

In Tunisia, olive trees cover an area of $1,700,000$ ha and account for more than $4 \%$ of the olive oil produced in the world. Indeed, Tunisia is the fourth largest exporter of olive oil in the world [1]. Due to the diversity of Tunisian olive cultivars, the olive-growing areas spread from north to south, where a wide range of pedoclimatic conditions prevail, from mild semi-arid to arid conditions. More than 50 different olive oil cultivars exist in Tunisia such as Chetoui in the north, Oueslati in the central part of the country, and Chemlali spread from the north-east of the country to the extreme south [2]. Chemlali is the main cultivar variety, covering $60 \%$ of the olive-growing surface [1]. It is characterized by relatively low levels of oleic acid (53-60\%), high levels of palmitic acid and a low oleic/linoleic acids ratio. Oil production is influenced by climatic, genetic, and agronomic factors as well as by their interactions. Ryan et al. [3] have shown that climatic factors such as temperature and precipitation have an effect on plant physiological behavior and, consequently, on the chemical characteristics of its oil. Thus, olive oil has become of a special interest and research has been conducted to ensure its purity, authenticity and quality $[4,5]$.

The importance accorded to virgin olive oils (VOO) is due not only to the presence of fatty acids, but also to their richness in important functional components, especially volatile compounds. Recently, an increasing demand for high-quality VOO is required by consumers because of its potential health benefits. Futhermore, many studies have suggested that stone removal gives rise to an increase in oxidative stability in the oils [6]. This may be explained by the absence of the olive seed during the crushingmalaxation process occurring in the olive oil production [6]. Thus, a technological procedure that includes stone removal before the olive oil extraction process is being developed. VOO is also world widely appreciated for its taste and aroma that is characterized by various volatile compounds: aldehydes, alcohols, esters, hydrocarbons, ketones, furans, and probably, other unidentified volatiles [7].

Many studies have been carried out to categorize virgin olive oils from different geographical origins according to their different chemical compositions. However, to the best of our knowledge, there is no study on the chemical compositions and sensory profiles of different parts (fruits, pulps, and seeds) of olives, particularly for the Tunisian cultivars.

The present research reports the content of fatty acids, squalene, aroma profiles, and sensory properties of virgin olive oils from pulp, seeds, and whole olive fruits during the maturation of two Tunisian cultivars (Chemlali and Oueslati) located in the center of Tunisia.

\section{Material and methods}

\subsection{Chemicals and reagents}

Methanol, hexane, acetic acid, and cyclohexane HPLCgrade solvents were purchased from Riedel-deHaen (Switzerland). The double distilled water was used as HPLC mobile phase. Folin-Ciocalteu reagent was obtained from Fluka (Switzerland), Squalene ( $\geq 98 \%$ ), from SigmaAldrich (Steichein, Germany).

\subsection{Samples}

Twelve oil samples were obtained from homogenous whole olive fruits, pulps and seeds (Olea europaea L.) of Chemlali $(\mathrm{CH})(n=6)$ and Oueslati (OU) $(n=6)$ cultivars grown in centre of Tunisia (Kairouan). The olives were picked by hand during the crop season 2012 at two stages of maturity: maturity index (MI) 1 and 5.42 for Chemlali and 1 and 5.23 for Oueslati. The maturity index (MI) was determined by the visual appreciation of color of olives from three trees $(n=3 \times 100)$, randomly selected, according to the method developed by Uceda et al. [8] which attribute a maturity index range from 0 (for unripe fruits) to 7 (ripe fruits). Only healthy fruits, without any kind of infection or physical damage, were processed. after harvesting, fresh olives $(4 \mathrm{~kg})$ were deleafed and washed. The pulps $(3.5 \mathrm{~kg})$ and stones $(3.2 \mathrm{~kg})$ were prepared from $5 \mathrm{~kg}$ and $10 \mathrm{~kg}$ respectively of fresh olives by hand in the laboratory. Fruit and pulp olive oils were obtained by extraction with laboratory mill (a two-phase decanter centrifuge, using an abencor system) and seed oils $(40 \mathrm{~mL})$ were obtained by cold press. all oil samples were stored at $4{ }^{\circ} \mathrm{C}$ in the darkness, using amber glass bottles without headspace, until analysis.

\subsection{Sample designations}

Chemlali cultivar: $\mathrm{FC} 1$ : whole fruit oil, $\mathrm{MI}=1 ; \mathrm{FC} 2$ : whole fruit oil, $\mathrm{MI}=5.42 ; \mathrm{PC} 1$ : pulp oil: $\mathrm{MI}=1 ; \mathrm{PC} 2$ : pulp oil, $\mathrm{MI}=5.42 ; \mathrm{SC} 1$ : seed oil, $\mathrm{MI}=1 ; \mathrm{SC} 2$ : seed oil, $\mathrm{MI}=5.42$;

Oueslati cultivar: $\mathrm{FO} 1$ : whole fruit oil, $\mathrm{MI}=1 ; \mathrm{FO} 2$ : whole fruit oil, $\mathrm{MI}=5.23$; PO1: pulp oil, $\mathrm{MI}=1 ; \mathrm{PO} 2$ : pulp oil, $\mathrm{MI}=5.23$; SO1: seed oil, $\mathrm{MI}=1$; $\mathrm{SO} 2$ : seed oil, $\mathrm{MI}=5.23$.

\subsection{Analytical methods}

\subsubsection{Quality index determinations}

The determination of acidity (a) (given as $\%$ of oleic acid), peroxide value (PV) (meqO $/ 2$ of oil), $\mathrm{K}_{232}$, and $\mathrm{K}_{270}$ were carried out according to International Organization for Standardization (ISO) standard methods $[9,10]$ and the International Olive Council IOC method [11] respectively. 


\subsubsection{Pigment content}

Chlorophyll and carotenoids were determined colorimetrically as previously described by Minguez-Mosquera et al., [12].

\subsubsection{Fatty acid and squalene compositions}

Olive oil in $n$-heptane $(0.12 \mathrm{~g} / 2 \mathrm{~mL})$ was transmethylated using a cold solution of $\mathrm{KOH}(2 \mathrm{M})(200 \mu \mathrm{L})$ according to the European Standard NF EN ISO 5509 Norm (2000) [13]. Fatty acid methyl esters (FaMEs) were analyzed according to the European Standard NF EN ISO 5508 Norm (1995) [14]. analyses were performed on an agilent Technology gas chromatograph 7890 a (GC) equipped with a split/split-less injector $\left(t=250^{\circ} \mathrm{C}\right.$ ) and flame ionization detector (FID) $\left(t=250^{\circ} \mathrm{C}\right)$. a silica capillary column $(60 \mathrm{~m} \times 0.25 \mathrm{~mm}$ i.d., $0.25 \mu \mathrm{m}$ film thickness) coated with Sulpelcowax (Supelco, Bellefonte, $\mathrm{Pa}, \mathrm{USa}$ ) was used. The inlet pressure of the hydrogen as carrier gas was $178 \mathrm{kPa}$ with a ratio1:70. The oven temperature program was as follows: $20 \mathrm{~min}$ at $210^{\circ} \mathrm{C}$, from 210 to $245^{\circ} \mathrm{C}$ at $6^{\circ} \mathrm{C} / \mathrm{min}, 20 \mathrm{~min}$ at $245^{\circ} \mathrm{C}$. The identification of fatty acids was performed by the comparison of retention times with those of olive oil fatty acids, whose composition is known. Fatty acid percentages were determined by internal standardization without taking into account mass response factors [15]. The coefficients of variation were lower than $5 \%$ for the most important FaMEs and lower than $10 \%$ for some minor ones.

Squalene, whose peak is well separated from that of C24:0 (retention times 38.48 and $37.55 \mathrm{~min}$. respectively) was determined along with the fatty acids using an external standard calibration curve (Eq.1).

$\mathrm{A}=214.32 \mathrm{C}-0.21$

where $\mathrm{A}$ is the peak area of squalene, and $\mathrm{C}$ is the concentration expressed in $\mathrm{mg} / \mathrm{mL}$ ) (linearity: 0.030 $\left.0.60 \mathrm{mg} / \mathrm{mL}, R^{2}=0,999\right)$. Final results, calculated on the basis of the analyzed oil weight, were expressed in $\mathrm{mg} / \mathrm{kg}$ with a coefficient of variation equal to $1.5 \%$ according to the experimental error.

\subsubsection{Volatile compound analyses}

Extraction. Solid-phase micro extraction was used as a technique for headspace sampling of virgin olive oils. Supelco SPME devices coated with polydimethylsiloxane (PDMS, $100 \mu \mathrm{m}$ ) were used to sample the headspace of $2 \mathrm{~mL}$ of olive oil inserted into a $5 \mathrm{~mL}$ glass septum vial and allowed to equilibrate for $30 \mathrm{~min}$ at $22 \pm 1^{\circ} \mathrm{C}$. after the equilibration time, the fiber was exposed to the headspace for $50 \mathrm{~min}$. Extraction temperature and times were optimized in previous studies [16].
Identification. GC analyses were performed using a HP5890 series II instrument equipped with a DB-5 capillary column $(30 \mathrm{~m} \times 0.25 \mathrm{~mm}$ i.d., $0.25 \mu \mathrm{m}$ film thickness), working with the following temperature program: $60^{\circ} \mathrm{C}$ for $10 \mathrm{~min}$, ramp of $5^{\circ} \mathrm{C} \mathrm{min} 1-220^{\circ} \mathrm{C}$; injector and detector temperatures, $250^{\circ} \mathrm{C}$; carrier gas, helium $\left(1 \mathrm{~mL} \mathrm{~min}^{-1}\right)$; detector FID; splitless injection. The components were identified by the comparison of their retention times with those of pure authentic standards and by means of their linear retention indices (LRI) relative to the series of $n$-alkanes. GC-EIMS analyses were performed using a Varian CP 3800 gas-chromatograph equipped with a DB-5 capillary column (30 $\mathrm{m} \times 0.25 \mathrm{~mm}$ i.d., $0.25 \mu \mathrm{m}$ film thicknesses) and a Varian Saturn 2000 ion trap mass detector. The analytical conditions were as follow: injector and transfer line temperature at 250 and $240^{\circ} \mathrm{C}$, respectively; oven temperature was programmed from 60 to $240^{\circ} \mathrm{C}$ at $3^{\circ} \mathrm{C} \mathrm{min}^{-1}$; carrier gas, helium at $1 \mathrm{~mL} \mathrm{~min}^{-1}$; splitless injection. The identification of the constituents was based on the comparison of the retention times with those of authentic samples, comparing their LRI relative to the series of $n$-hydrocarbons, and on computer matching against commercial (NIST 98 and aDaMS) and home-made library mass spectra built from pure substances and components of known oils and MS literature data [17]. Moreover, the molecular weights of all the identified substances were confirmed by GC-CIMS, using $\mathrm{MeOH}$ as $\mathrm{CI}$ ionizing gas [18].

\subsubsection{Sensory assessment}

Sensory evaluation was carried out by a panel of eight judges (males between 45 and 52 years) who were fully trained in the evaluation of Virgin Olive Oil according to the official methods of the IOC [11].

\subsubsection{Statistical analysis}

The results were expressed as mean \pm standard deviation (SD) of three measurements for the analytical determination. Significant differences between the values of all parameters were determined at $p<0.05$ according to the one-way ANOVA: Student Newman-Keuls test, using SPSS Statistics 17.0 for Windows (SPSS Inc., 2008).

Non-standardized principal component analysis (PCA) was applied to show the effect of all the investigated parameters $(n=30)$ : Free fatty acids, peroxide value, $\mathrm{K}_{232}$, $\mathrm{K}_{270}$, chlorophylls, carotenoids, fourteen fatty acids, squalene, monoterpene hydrocarbons, oxygenated monoterpenes, sesquiterpene hydrocarbons, apocarotenoids, nonterpene derivatives, total aldehydes, total alcohols, total $\mathrm{C}_{6}$ aldehydes, and total $\mathrm{C}_{6}$ alcohols on the olive oils of the two cultivars using the Varimax rotation with Kaiser Normalization. The PCA type was Pearson $(n)$, the biplot type was correlation biplot and the coefficient was automatic. 
A uniform hierarchical cluster analysis (HCA) methodology was applied on data. Each cluster was determined by the following parameters: Dissimilarity, Euclidean distance matrix and the Ward's method, generating a dendrogram for the Chemlali and Oueslati olive oil samples. all the chemometric analyses were performed using XLSTAT software of Windows (v.2013.2.03, addinsoft, New York, USa).

\subsubsection{Nomenclature}

Fatty acids: 14:0, myristic acid (tetradecanoic acid); 16:0, palmitic acid (hexadecanoic acid); 16:1n-9, hypogeic acid, (7-hexadecenoic acid); 16:1n-7, palmitoleic acid (9-hexadecenoic acid); 17:0, margaric acid (heptadecanoic acid); 17:1n-8, margaroleic acid, (9-heptadecenoic acid); 18:1n-9, oleic acid (9-octadecenoic acid); 18:1n-7, cis vaccenic acid (11-octadecenoic acid); 18:2n-6, linoleic acid (9,12-octadecadienoic acid); 18:3n-3, linolenic acid (9,12,15-octadecatrienoic acid); 20:0, arachidic acid (eicosanoic acid); 20:1n9, gondoic acid (11-eicosenoic acid); 22:0, behenic acid (docosanoic acid); 24:0, lignoceric acid (tetracosanoic acid).

\section{Results and discussion}

\subsection{Quality indices}

The quality indices of Chemlali and Oueslati whole fruit, pulp and seed oils are listed in Table 1. acidity is an important quality index that has been extensively used as a traditional criterion for classifying olive oil in various commercial grades of International Olive Council [11]. although acidity increased with maturity index in the fruits and pulps of both varieties (Chemlali: fruits, $0.31-0.58 \%$; pulps, $0.28-$ $0.61 \%$. Oueslati: fruits, $0.41-0.65 \%$; pulps, $0.33-0.58 \%$ ), it remained less than $0.8 \%$, which categorizes oils as extra virgin. Not only seed oils had a higher acidity than the fruits and seeds $(>0.8 \%)$, but acidity also increased with the maturity index (Chemlali: seeds, $1.20-1.54 \%$; Oueslati: seeds, $1.35-1.69 \%$ ). The high acidity of seed oils may be explained by the presence of a lipase activity which hydrolyses the triacylglycerols $[19,20]$.

The peroxide values decrease in the fruits and pulps of both varieties with the maturity index (Chemlali: fruits, $13.25-8.68 \%$, pulps $15.43-9.32 \%$; Oueslati fruits, $12.31-$ $7.35 \%$, pulps $13.50-8.34 \%$ ). PV did not exceed the maximum limit, established by IOC [11] for the extra virgin olive oil category $\left(<20 \mathrm{meqO}_{2} / \mathrm{kg}\right)$. PVs of seed oils also decreased with maturity index but they were much higher than those of fruit and pulp oils (Chemlali: $22.74-18.28 \%$; Oueslati: $25.81-21.37 \%$ ).

Specific extinction $\mathrm{K}_{232}$ and $\mathrm{K}_{270}$ decreased for the oils of fruits, pulp, and seeds of Chemlali and Oueslati with the maturity index. $\mathrm{K}_{232}$ varied between 1.43-2.18, 1.65-2.09, and $\mathrm{K}_{270} 0.11-0.18,0.12-0.17$ for fruits and pulps of $\mathrm{CH}$ oils. For the OU oils, they vary between $1.54-2.28,1.72$ $2.17,0.12-0.17,0.11-0.18$ for fruits and pulps for the K232 and $\mathrm{K} 270$ respectively. In both cases, $\mathrm{K}_{232}$ and $\mathrm{K}_{270}$ were in accordance with the values recommended by the IOC [11] which allows for their characterization as extra virgin olive oil the following values: $\mathrm{K}_{232} \leq 2.50$ and $\mathrm{K}_{270} \leq 0.22$.

The similarity between the values of the quality indices of the fruit and pulp oils may be explained by the small contribution of seeds in the fruit oils.

\subsection{Chlorophyll and carotenoid contents}

Green, yellowish-green or yellow colors of olive oils are due to various pigments: chlorophylls, pheophytins, and carotenoids (lutein). These pigments are involved in the stability of olive oils.

The contents in chlorophylls and carotenoids in the olive oils of Chemlali and Oueslati fruits, pulps and seeds decreased when the maturity index increased, showing the loss of pigments as the ripening progresses which confirms the results of Lazzez et al. [21]. For the oil of Chemlali fruits. For both varieties at equivalent maturity index, the fruit oils had higher carotenoid and chlorophyll contents than those of oils pulp. In fact, for $\mathrm{CH}$ and $\mathrm{OU}$ fruits, carotenoids varied from $0.95-1.89,1.36-2.17,0.78-1.72$, and $0.97-1.94 \mathrm{mg} / \mathrm{kg}$ for fruits and pulp of $\mathrm{CH}$ and $\mathrm{OU}$ oils and chlorophylls from $0.95-1.93,1.13-2.06,0.86-1.74$, and $1.04-1.98 \mathrm{mg} / \mathrm{kg}$ for fruits and pulp of $\mathrm{CH}$ and $\mathrm{OU}$ oils. These results showing the loss of pigments as the ripening progresses are in good accord with those of other authors [21].

The seeds oils had higher contents in chlorophylls and carotenoids than those of the fruits and pulps. The contents in carotenoids varied according to the $\mathrm{MI}$ for $\mathrm{CH}$ and $\mathrm{OU}$ from 3.41 to $4.08 \mathrm{mg} / \mathrm{kg}$ and 3.16 to $3.84 \mathrm{mg} / \mathrm{kg}$, respectively. The contents in chlorophylls also varied according to the MI for $\mathrm{CH}$ and $\mathrm{OU}$ from 2.91 to $3.74 \mathrm{mg} / \mathrm{kg}$ and 4.85 to $6.11 \mathrm{mg} /$ $\mathrm{kg}$, respectively.

\subsection{Fatty acid compositions}

The fatty acid compositions are reported in Table 2 . Fourteen fatty acids, together with squalene, were identified in the oils obtained from whole fruits, pulps and seeds. Oleic acid (18:1n-9), palmitic acid (16:0), linoleic acid (18:2n-6), and stearic acid (18:0) were the main fatty acids in all olive oils. The ten other fatty acids were detected in low percentages. Monounsaturated isomers of fatty acids with sixteen carbon atoms (hypogeic acid: 16: $1 \mathrm{n}-9$ and palmitoleic acid: $16: 1 \mathrm{n}-7$ ) and eighteen carbon atoms (oleic acid: 18: 1n-9 and z-vaccenic acid: 18: 1n-7) are considered separately contrary to the commercial standards (trade standard) of the IOC (2013) [11]. The determination of these minor fatty acids is very important for the accurate knowledge of lipid profiles during the authentication of the varietal origin of olive oils [15]. 
Table 1. Quality of olive oils obtained from whole fruits, pulps and seeds of two Tunisian cultivars

\begin{tabular}{|c|c|c|c|c|c|c|}
\hline \multirow[b]{3}{*}{ MI } & \multicolumn{6}{|c|}{ Chemlali } \\
\hline & \multicolumn{2}{|c|}{ Fruits } & \multicolumn{2}{|c|}{ Pulps } & \multicolumn{2}{|c|}{ Seeds } \\
\hline & 1 & 5.42 & 1 & 5.42 & 1 & 5.42 \\
\hline Free Fatty acid (\% Oleic) & $0.31 \pm 0.00^{\mathrm{a}}$ & $0.58 \pm 0.02^{\mathrm{b}}$ & $0.28 \pm 0.00^{\mathrm{m}}$ & $0.61 \pm 0.02^{\mathrm{n}}$ & $1.20 \pm 0.04^{\mathrm{w}}$ & $1.54 \pm 0.05^{\mathrm{x}}$ \\
\hline Peroxide value (meq $\mathrm{O}_{2} / \mathrm{Kg}$ ) & $13.25 \pm 0.39^{\mathrm{a}}$ & $8.68 \pm 0.22^{\mathrm{b}}$ & $15.43 \pm 0.35^{\mathrm{m}}$ & $9.32 \pm 0.31^{\mathrm{n}}$ & $22.74 \pm 0.88^{\mathrm{w}}$ & $18.28 \pm 0.21^{\mathrm{x}}$ \\
\hline $\mathrm{K}_{232}$ & $2.18 \pm 0.10^{\mathrm{a}}$ & $1.43 \pm 0.05^{\mathrm{b}}$ & $2.09 \pm 0.07^{\mathrm{m}}$ & $1.65 \pm 0.04^{\mathrm{n}}$ & $4.68 \pm 0.18^{\mathrm{w}}$ & $3.17 \pm 0.13^{\mathrm{x}}$ \\
\hline $\mathrm{K}_{270}$ & $0.18 \pm 0.00^{\mathrm{a}}$ & $0.11 \pm 0.00^{\mathrm{b}}$ & $0.17 \pm 0.00^{\mathrm{m}}$ & $0.12 \pm 0.00^{\mathrm{n}}$ & $0.29 \pm 0.01^{\mathrm{w}}$ & $0.24 \pm 0.01^{\mathrm{x}}$ \\
\hline Carotenoids (ppm) & $1.89 \pm 0.05^{\mathrm{a}}$ & $0.95 \pm 0.03^{\mathrm{b}}$ & $1.72 \pm 0.05^{\mathrm{m}}$ & $0.78 \pm 0.02^{\mathrm{n}}$ & $4.08 \pm 0.12^{\mathrm{w}}$ & $3.41 \pm 0.11^{\mathrm{x}}$ \\
\hline \multirow[t]{3}{*}{ Chlorophylls (ppm) } & $1.93 \pm 0.05^{\mathrm{a}}$ & $0.95 \pm 0.03^{\mathrm{b}}$ & $1.74 \pm 0.04^{\mathrm{m}}$ & $0.86 \pm 0.02^{\mathrm{n}}$ & $3.74 \pm 0.13^{\mathrm{w}}$ & $2.91 \pm 0.08^{\mathrm{x}}$ \\
\hline & \multicolumn{6}{|c|}{ Oueslati } \\
\hline & \multicolumn{2}{|c|}{ Fruits } & \multicolumn{2}{|c|}{ Pulps } & \multicolumn{2}{|c|}{ Seeds } \\
\hline MI & 1 & 5.23 & 1 & 5.23 & 1 & 5.23 \\
\hline Free Fatty acid (\% Oleic) & $0.41 \pm 0.02^{\mathrm{c}}$ & $0.65 \pm 0.03^{\mathrm{d}}$ & $0.33 \pm 0.01^{\circ}$ & $0.58 \pm 0.02^{\mathrm{p}}$ & $1.35 \pm 0.05^{\mathrm{y}}$ & $1.69 \pm 0.04^{z}$ \\
\hline Peroxide value (meq $\mathrm{O}_{2} / \mathrm{Kg}$ ) & $12.31 \pm 0.18^{\mathrm{c}}$ & $7.35 \pm 0.19^{\mathrm{d}}$ & $13.50 \pm 0.15^{\circ}$ & $8.34 \pm 0.13^{\mathrm{p}}$ & $25.81 \pm 0.92^{\mathrm{y}}$ & $21.37 \pm 0.24^{\mathrm{z}}$ \\
\hline $\mathrm{K}_{232}$ & $2.28 \pm 0.07^{\mathrm{c}}$ & $1.54 \pm 0.06^{\mathrm{d}}$ & $2.17 \pm 0.09^{\mathrm{m}}$ & $1.72 \pm 0.05^{\mathrm{n}}$ & $4.19 \pm 0.13^{\mathrm{y}}$ & $3.36 \pm 0.14^{\mathrm{x}}$ \\
\hline $\mathrm{K}_{270}$ & $0.17 \pm 0.01^{\mathrm{c}}$ & $0.12 \pm 0.00^{\mathrm{d}}$ & $0.18 \pm 0.00^{\circ}$ & $0.11 \pm 0.00^{\mathrm{p}}$ & $0.31 \pm 0.01^{\mathrm{y}}$ & $0.25 \pm 0.01^{\mathrm{x}}$ \\
\hline Carotenoids (ppm) & $2.17 \pm 0.07^{\mathrm{c}}$ & $1.36 \pm 0.02^{\mathrm{d}}$ & $1.94 \pm 0.03^{\circ}$ & $0.97 \pm 0.04^{\mathrm{p}}$ & $3.84 \pm 0.15^{\mathrm{y}}$ & $3.16 \pm 0.13^{\mathrm{z}}$ \\
\hline Chlorophylls (ppm) & $2.06 \pm 0.06^{\mathrm{c}}$ & $1.13 \pm 0.02^{\mathrm{d}}$ & $1.98 \pm 0.07^{\circ}$ & $1.04 \pm 0.02^{\mathrm{p}}$ & $6.11 \pm 0.25^{\mathrm{y}}$ & $4.85 \pm 0.17^{\mathrm{z}}$ \\
\hline
\end{tabular}

MI, Maturity index, Each value represents the mean of three determinations $(n=3) \pm$ standard deviation.

a, b, c and d Different letters in the same line concerning all samples fruits indicate significantly different values $(p<0.05)$.

$\mathrm{m}, \mathrm{n}, \mathrm{o}$ and $\mathrm{p}$ Different letters in the same line concerning samples pulps indicate significantly different values $(p<0.05)$..

$\mathrm{w}, \mathrm{x}, \mathrm{y}$ and $\mathrm{z}$ Different letters in the same line concerning samples seeds indicate significantly different values $(p<0.05)$.

The oils of $\mathrm{CH}$ and $\mathrm{OU}$ fruits had different fatty acid compositions. at the same maturity index, for example $\mathrm{MI}=1, \mathrm{CH}$ had higher percentages of palmitic acid (16:0, $19.25 \%)$, linoleic acid $(18: 2 \mathrm{n}-6,15.29 \%)$ than OU (16:0, $14.36 \%)$ and $(18: 2 n-6,10.61 \%)$. Conversely, OU was richer in oleic acid $(18: 1 \mathrm{n}-9,68.69 \%)$ than $\mathrm{CH}(18: 1 \mathrm{n}-9,58.47 \%)$. The percentages of palmitoleic acid and z-vaccenic acid are higher in $\mathrm{CH}$ oil $(\mathrm{MI}=1.16: 1 \mathrm{n}-7 ; 2.02 \% .18: 1 \mathrm{n}-7 ; 3.07 \%)$ than the OU oil $(\mathrm{MI}=1.16: 1 \mathrm{n}-7 ; 1.18 \% .18: 1 \mathrm{n}-7 ; 2.47 \%)$.

Fruits and pulp oils of the same variety and the same MI had similar fatty acids compositions. This result was expected because of the low contribution of the seed into the oil obtained from the entire fruit.

The $\mathrm{CH}$ and $\mathrm{OU}$ seed oils have fatty acid compositions that are different from those of fruit or pulp oils of both varieties. The $\mathrm{CH}$ seed oil contained lower percentages of palmitic acid than fruit and pulp oils. It increased with the maturity index $(\mathrm{MI}=1: 9.16 \% ; \mathrm{MI}=5.42: 14.25 \%)$. Oleic acid in $\mathrm{CH}$ seed oils was higher $(68.67 \%)$ for $\mathrm{MI}=1$ than in fruit and pulp oils and decreased (57.49\%) with MI. The major fatty acid compositions of OU seed oil did not vary in the same way. The palmitic acid percentages were lower than those found in OU fruit and pulp oils and decreased with the increase in maturity. Oleic acid in the same abundance in fruits and pulps varied slightly with the MI. The linoleic acid percentages in seed oils were significantly higher than in the fruit and pulp oils and slightly varied with the maturity index. The minor fatty acids of seed oils also showed differences compared to those of fruits and pulp. Thus, palmitoleic acid $(16: 1 \mathrm{n}-7), \mathrm{z}$-vaccenic acid $(18: 1 \mathrm{n}-7)$ and linolenic acid $(18: 3 n-3)$ were detected at lower percentages than in the fruit and pulp oils, whereas stearic acid (18:0), arachidic acid (20:0), gondoic acid (20:1n-9), behenic acid (22:0) and lignoceric acid (24:0) were present in higher amounts.

\subsection{Squalene contents}

Squalene is the major hydrocarbon in olive oil. In fact, this terpenoid makes up more than $90 \%$ of the hydrocarbon fraction [22].

The squalene content in $\mathrm{CH}$ and $\mathrm{OU}$ fruit, pulp and seed oils decreased with the increase in maturity index $(45 \%$ overall). For each variety and the same MI, they were similar in fruit and pulp oils and consistent with squalene contents quantified in olive oils $[22,23]$. Respectively in fruit oils and pulp oils, for $\mathrm{MI}=1$, they are equal to 2232 and $2330 \mathrm{mg} / \mathrm{kg}$ for $\mathrm{CH}$ and to 4994 and $5823 \mathrm{mg} / \mathrm{kg}$ for $\mathrm{OU}$ and for $\mathrm{MI}=5.42$, to 1185 and $1268 \mathrm{mg} / \mathrm{kg}$ for $\mathrm{CH}$ and to 2688 and $3221 \mathrm{mg} / \mathrm{kg}$ for OU. Furthermore, they are higher for OU variety. In contrast, contents of squalene in $\mathrm{CH}$ seed oils 
Table 2. Fatty acid compositions (\%) and squalene contents $(\mathrm{mg} / \mathrm{kg})$ of Chemlali and Oueslati oils from different parts of olives at different maturities

\begin{tabular}{|c|c|c|c|c|c|c|c|c|c|c|c|c|}
\hline \multirow[b]{3}{*}{ MI } & \multicolumn{6}{|c|}{ Chemlali } & \multicolumn{6}{|c|}{ Oueslati } \\
\hline & \multicolumn{2}{|c|}{ Fruits } & \multicolumn{2}{|c|}{ Pulps } & \multicolumn{2}{|c|}{ Seeds } & \multicolumn{2}{|c|}{ Fruits } & \multicolumn{2}{|c|}{ Pulps } & \multicolumn{2}{|c|}{ Seeds } \\
\hline & 1 & 5.42 & 1 & 5.42 & 1 & 5.42 & 1 & 5.23 & 1 & 5.23 & 1 & 5.23 \\
\hline $\mathrm{C} 16: 0$ & 19.25 & 17.73 & 18.99 & 18.11 & 9.16 & 14.25 & 14.36 & 11.73 & 15.07 & 12.09 & 9.59 & 8.67 \\
\hline $\mathrm{C} 16: 1 \mathrm{n}-9+\mathrm{C} 16: 1 \mathrm{n}-7$ & 2.08 & 2.28 & 2.00 & 2.16 & 0.46 & 1.61 & 1.28 & 0.90 & 1.40 & 0.89 & 0.56 & 0.45 \\
\hline $\mathrm{C} 16: 1 \mathrm{n}-7$ & 2.02 & 2.22 & 1.95 & 2.10 & 0.40 & 1.55 & 1.18 & 0.79 & 1.30 & 0.79 & 0.49 & 0.37 \\
\hline C17:0 & 0.04 & 0.04 & 0.04 & 0.04 & 0.06 & 0.04 & 0.04 & 0.04 & 0.04 & 0.03 & 0.06 & 0.06 \\
\hline $\mathrm{C} 17: 1 \mathrm{n}-8$ & 0.06 & 0.07 & 0.07 & 0.07 & 0.06 & 0.06 & 0.06 & 0.05 & 0.06 & 0.04 & 0.05 & 0.06 \\
\hline $\mathrm{C} 18: 0$ & 2.46 & 2.30 & 2.39 & 2.38 & 3.13 & 2.79 & 2.38 & 2.16 & 2.23 & 2.19 & 3.19 & 3.21 \\
\hline $\mathrm{C} 18: 1 \mathrm{n}-9+\mathrm{C} 18: 1 \mathrm{n}-7$ & 58.47 & 56.28 & 59.63 & 56.64 & 68.67 & 57.49 & 68.69 & 71.59 & 67.46 & 71.54 & 67.78 & 69.45 \\
\hline C18:1n-7 & 3.07 & 3.27 & 3.07 & 3.14 & 1.44 & 2.48 & 2.47 & 2.03 & 2.68 & 2.05 & 1.40 & 1.27 \\
\hline$C 18: 2 n-6$ & 15.29 & 19.69 & 14.62 & 19.01 & 16.28 & 22.00 & 10.61 & 11.36 & 10.90 & 11.06 & 16.63 & 16.11 \\
\hline$C 18: 3 n-3$ & 1.03 & 0.66 & 0.97 & 0.65 & 0.41 & 0.50 & 0.84 & 0.69 & 0.99 & 0.66 & 0.41 & 0.35 \\
\hline $\mathrm{C} 20: 0$ & 0.50 & 0.41 & 0.48 & 0.41 & 0.63 & 0.54 & 0.45 & 0.44 & 0.45 & 0.44 & 0.63 & 0.65 \\
\hline C20:1n-9 & 0.22 & 0.18 & 0.22 & 0.18 & 0.48 & 0.29 & 0.28 & 0.37 & 0.29 & 0.36 & 0.43 & 0.42 \\
\hline $\mathrm{C} 22: 0$ & 0.16 & 0.12 & 0.15 & 0.12 & 0.28 & 0.20 & 0.13 & 0.16 & 0.14 & 0.15 & 0.29 & 0.29 \\
\hline C24:0 & 0.10 & 0.06 & 0.09 & 0.05 & 0.14 & 0.11 & 0.08 & 0.08 & 0.09 & 0.08 & 0.16 & 0.15 \\
\hline Squalene & 2232 & 1185 & 2330 & 1268 & 1216 & 544 & 4994 & 2688 & 5823 & 3221 & 1254 & 740 \\
\hline C18:1/C18:2 & 3.82 & 2.86 & 4.08 & 2.98 & 4.22 & 2.61 & 6.47 & 6.30 & 6.18 & 6.47 & 4.08 & 4.31 \\
\hline$\sum \mathrm{SFA}$ & 22.51 & 20.66 & 22.14 & 21.11 & 13.40 & 17.93 & 17.44 & 14.61 & 18.02 & 14.98 & 13.92 & 13.03 \\
\hline$\sum M U F A$ & 60.83 & 58.81 & 61.92 & 59.05 & 69.67 & 59.45 & 70.31 & 72.91 & 69.21 & 72.83 & 68.82 & 70.38 \\
\hline$\sum$ PUFA & 16.32 & 20.35 & 15.59 & 19.66 & 16.69 & 22.50 & 11.45 & 12.05 & 11.89 & 11.72 & 17.42 & 16.46 \\
\hline$\sum \mathrm{UFA}$ & 77.15 & 79.16 & 77.51 & 78.71 & 86.36 & 81.95 & 81.76 & 84.96 & 81.10 & 84.55 & 85.86 & 86.84 \\
\hline$\sum \mathrm{MUFA} / \sum \mathrm{PUFA}$ & 3.73 & 2.89 & 3.97 & 3.00 & 4.17 & 2.64 & 6.14 & 6.05 & 5.82 & 6.21 & 4.04 & 4.28 \\
\hline
\end{tabular}

SFA, saturated fatty acids; MUFA, monounsaturated fatty acids; PUFA, polyunsaturated fatty acids; UFA, unsaturated fatty acids; MI, maturity index.

$(\mathrm{MI}=1,1216 \mathrm{mg} / \mathrm{kg} ; \mathrm{MI}=5.42,544 \mathrm{mg} / \mathrm{kg})$ and those of OU $(\mathrm{MI}=1, \quad 1254 \mathrm{mg} / \mathrm{kg} ; \quad \mathrm{MI}=5.23,740 \mathrm{mg} / \mathrm{kg})$ were similar and lower than those found in fruit and pulp oils. Moreover, they decreased in a more pronounced way in $\mathrm{CH}$ seed oils ( 55 vs. $41 \%$ ).

\subsection{Volatile compounds in samples}

Aroma is an important quality criterion for virgin olive oils. Consequently, the identification of the compounds contributing to its aroma is considered as a key for quality and authentication control. In fact, volatile components of olive oil are of great interest since they are not only related to its quality but they are also used to detect adulteration [24].

Many analytical procedures have been used to isolate, identify, and quantify the volatile components that characterize olive oil aroma [25]. among these extraction techniques, solid phase micro-extraction (SPME) is a solvent-free sample preparation technique for the sampling of volatile and nonvolatile compounds. It is also a simple and fast technique to implement and to be coupled with GC-RI and GC-MS. The results have shown that the virgin olive oil aroma consist of a complex mixture of sixty-six compounds, representing
92.4-97.6\% of the total GC area (Table 3). Furthermore, in the headspace of all oil samples, the isolated and identified compounds were mainly aldehydes (3.1-45.4\%), followed by alcohols (6.5-91.3\%), monoterpenes (0.0-15.2\%), sesquiterpenes (0.0-19.8\%), and apocarotenoids (0.0-1.4\%).

The products of the lipoxygenase pathway (LOX) were generally the major components of the volatile fraction and they ranged between 13.9 and $89.8 \%$ of the total volatiles (Table 3). In all the oil samples, the major components of the volatile fraction of virgin olive oils were the C6 compounds, which derived from the cascade of enzymatic reactions starting with the formation, by lipoxygenase action of 13 hydroperoxides from linoleic and linolenic acids [26]. They are also the main responsible for the green odour note. In the same way, $\mathrm{C}_{6}$ compounds had their biogenesis mainly in the olive pulps for the studied varieties as can be seen in Table 3 . The $\mathrm{C}_{6}$ alcohols content in Chemlali oil was higher than in Oueslati one. actually, in the oils obtained from pulps and whole fruits in Chemlali the former had the highest value, ranging from 56.6 to $89.0 \%$ and 36.9 to $41.5 \%$, respectively (Table 3). In the Oueslati oil, the C6 alcohols content in pulps and fruits oils ranged from 41 to $46.8 \%$ and 6.1 to $35.5 \%$, respectively. In the case of the seed oils, this content 


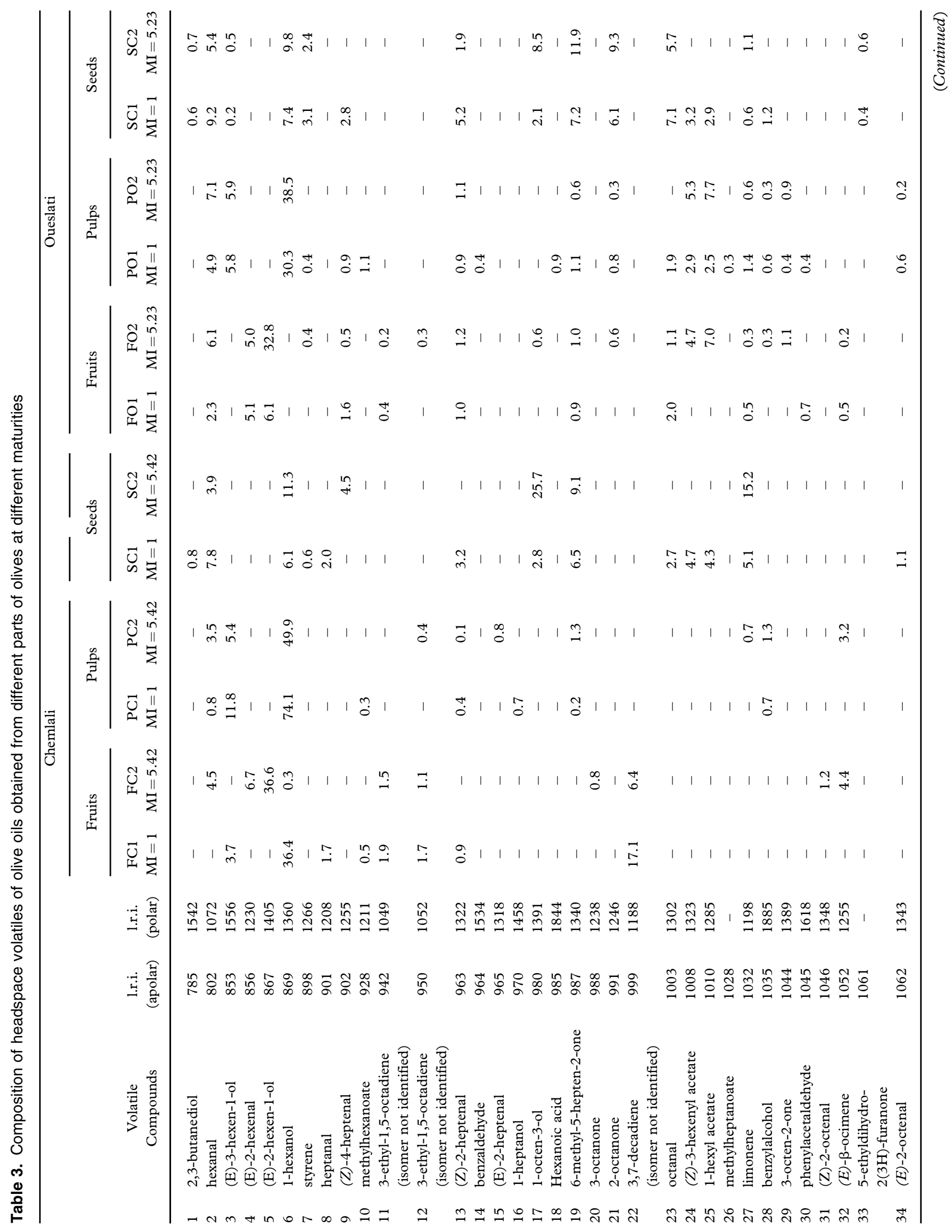




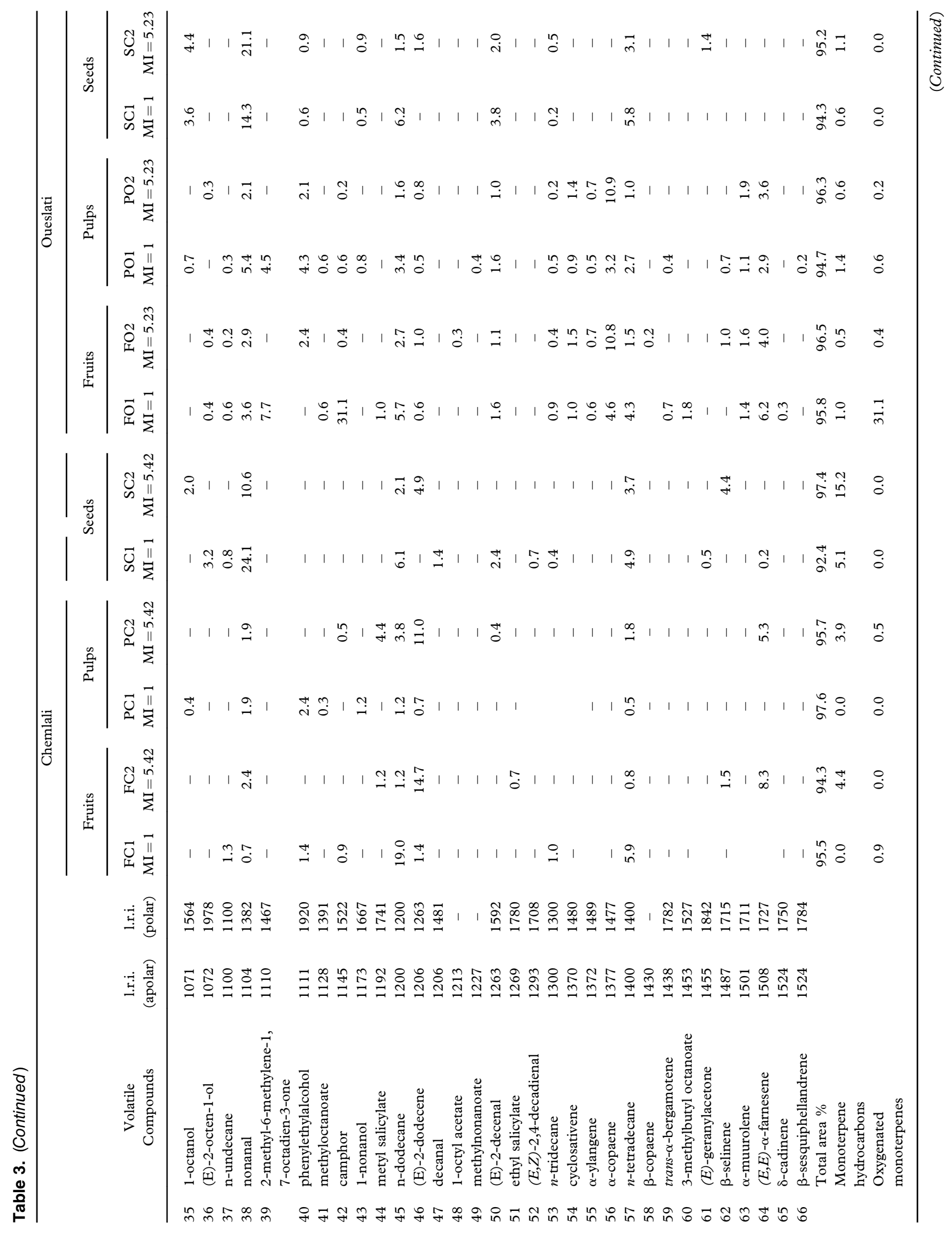




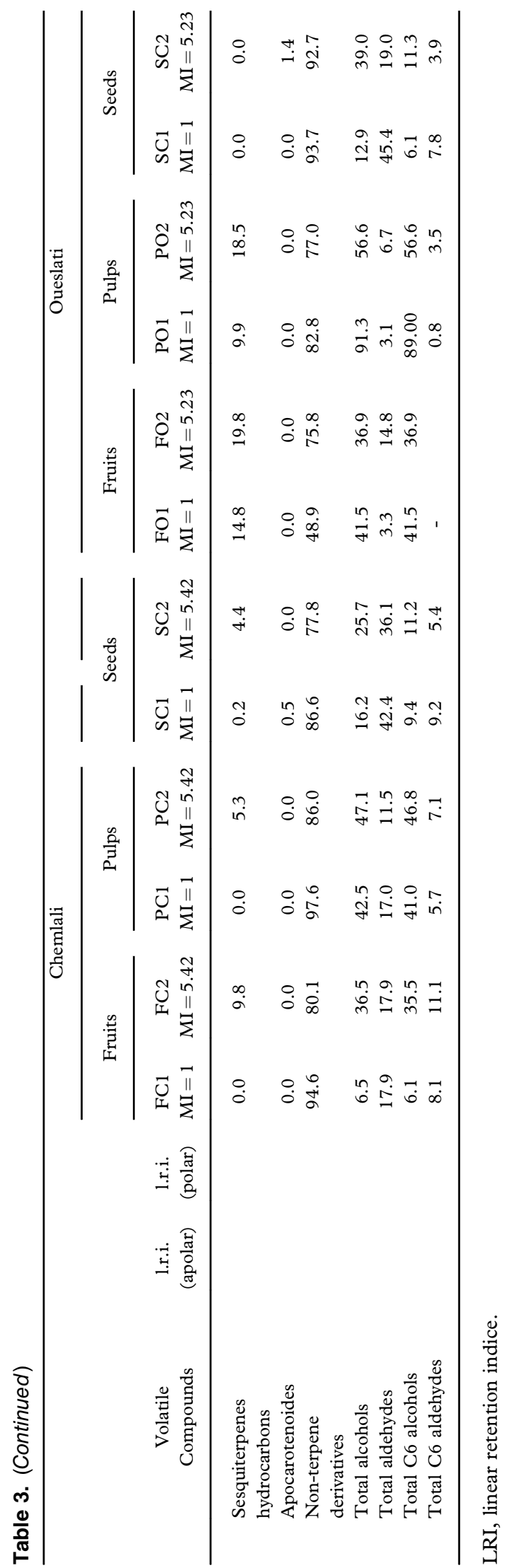

varied according to the maturation stage, until it reached a maximum (11.3\%) at stage two of olive ripening in Chemlali cultivar.

The LOX pathway is initiated by the release of enzymes as soon as the olive fruit tissues are disrupted. In the first step of volatile compounds formation, acyl hydrolase $\mathrm{aH}$, a group of enzymes that includes lipases, phospholipases, and galactolipases) hydrolyzed triglycerides and phospholipids to release free fatty acids [27]. Then, free fatty acids are oxidized by lipoxygenase (LOX) and cleaved by hydroperoxide lyase (HPL) to yield aldehydes.

LOX in olive pulp was more active with linolenic acid (Lna, 100\%) than with linoleic acid (La, 61\%) [28]. as a consequence of the cleavage of 13-hydroperoxide from La, hexanal was formed at lower concentration compared to the same biogenesis from Lna that led to the formation of the unsaturated aldehyde ((Z)-3-hexen-1-al) [29].

C6-aldehydes were subsequently reduced by alcohol dehydrogenase $(\mathrm{ADH})$ to alcohols (related to fruity, green, and grassy sensory notes), 1-hexanol was formed from La (using hexanal as substrate) and (E)-2-hexen-1-ol was formed from Lna (using (E)-2-hexen-1-al as substrate). These volatiles are mainly synthesized in the olive pulp. Higher concentrations of 1-hexanol with respect to (E)-2hexen-1-ol were registered for all samples except for three ones (Oueslati fruits and Chemlali fruits at stage two of olive ripening). The 1-hexanol content in oil pulp ranged from $30.3-38.5 \%$ (Oueslati cultivar) to $49.9-74.1 \%$ (Chemlali cultivar). The highest alcohol content in pulps was detected in the Chemlali cultivar.

Other minor volatile compounds were observed in some of the virgin olive oils samples. among these compounds, hydrocarbons and the aldehydes heptanal, octanal, nonanal, (E)-2-heptenal and (Z)-2-heptenal were formed because of autoxidation reactions [29], that inevitably starts after the virgin olive oil has been extracted.

In conclusion, as shown in Table 3, the chemical composition of the volatile fraction of olive oils was quite variable, depending on the harvesting period, the part of the olive used to obtain the oil and the cultivar.

\subsection{Sensory evaluation}

Figure 1 shows the positive descriptors (fruitiness, bitterness, and pungency) and the defects (musty and rancid) of the oils from fruits, pulps and seed of $\mathrm{CH}$ and $\mathrm{OU}$ obtained at two different maturity indices. The results indicated that the intensities of these attributes varied according to the cultivar, the olive parts used to obtain the oil, and the maturity index. The sensory analysis of Chemlali and Oueslati oils obtained from the whole fruits and pulps were similar and showed a moderately intense fruity flavor. Well-balanced bitter and pungent tastes are due in particular to the presence of oleuropein aglycon [30], and deacetoxy-ligustroside aglycon [31], with defect median equal to zero. according to the 
Chemlali
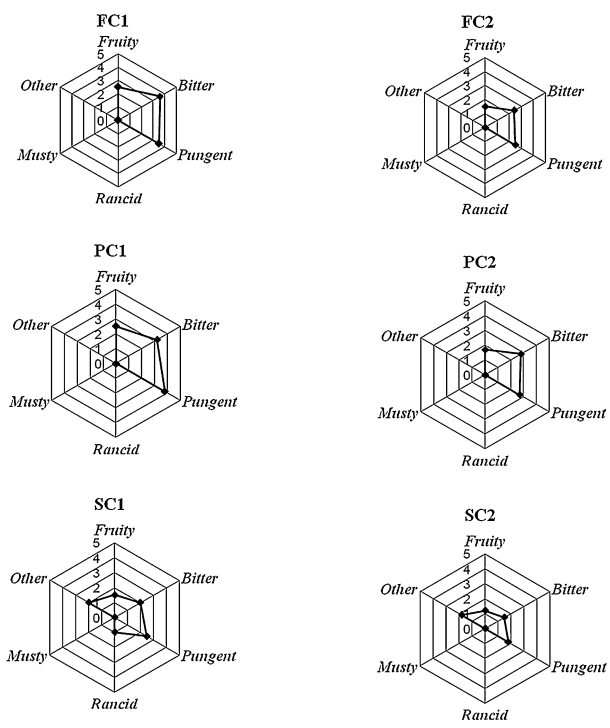

Oueslati
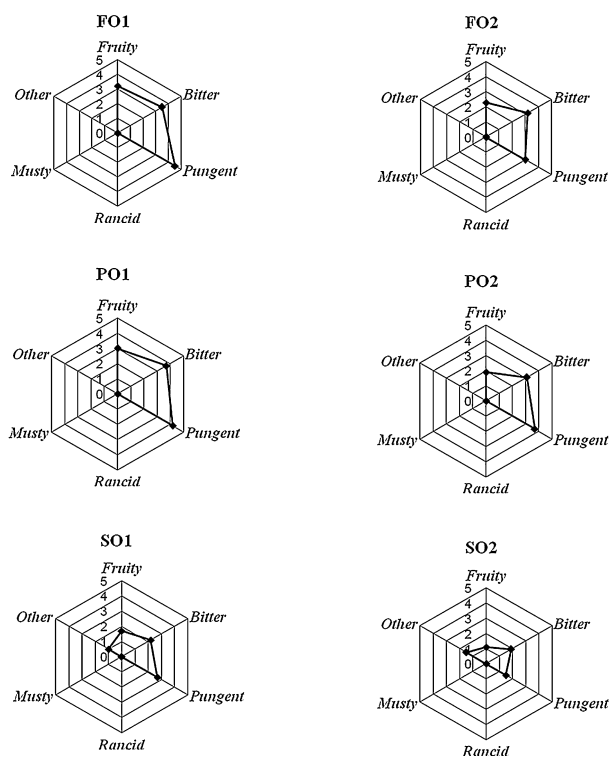

Figure 1. Sensory wheels of extra-virgin olive oils for the Tunisian olive cultivars: whole fruits, pulps and seeds of Chemlali and Oueslati varieties from Kairouan region. Other: means other the negative attributes; FC1: Olive Oil of whole fruits of Chemlali cultivar, $\mathrm{MI}=1$; $\mathrm{FC2}$ : Olive Oil of whole fruits of Chemlali cultivar, $\mathrm{MI}=5.42$; $\mathrm{PC} 1$ : Olive Oil of pulp of Chemlali cultivar, $\mathrm{MI}=1$; $\mathrm{PC} 2$ : Olive Oil of pulp of Chemlali cultivar, $\mathrm{MI}=5.42$; $\mathrm{SC1}$ : Olive Oil of seeds of Chemlali cultivar, $\mathrm{MI}=1$; SC2: Olive Oil of seeds of Chemlali cultivar, IM $=5.42 ; F O 1$ : Olive Oil of whole fruits of Oueslati cultivar, $\mathrm{MI}=1$; FO2: Olive Oil of whole fruits of Oueslati cultivar, $\mathrm{MI}=5.23$; $\mathrm{PO1}$ : Olives Oil of pulps of Oueslati cultivar, $\mathrm{MI}=1$; PO2: Olives Oil of pulps of Oueslati cultivar of Kairouan : $\mathrm{MI}=5.23$; SO1: Olive Oil seeds of Oueslati cultivar, $\mathrm{MI}=1$; $\mathrm{SO} 2$ : Olive Oil seeds of Oueslati cultivar, $\mathrm{MI}=5.23$. sensory evaluation, the oils under investigation belong to the extra virgin olive oil category. On the contrary, the sensory profile of the seed oils was quite different. In fact, a reduction in positive attributes, especially fruity flavor were apparent. It became clear that sensory quality was the result of the synergistic effect of the various oil components, which are influenced by the pedoclimatic conditions, ripening index and part of olive fruits used to extract the oil $[4,32]$.

\subsection{Chemometric analysis}

To evaluate the possibility of differentiating the samples taking into account 30 variables a multivariate statistical analysis was applied to the results. The application of the principal component analysis algorithm (PCA) has shown three distinct groups (Fig. 2a). By observing the eigenvalues, it can be concluded that two principal components $(F)$ were sufficient to account for $74.90 \%$ of the total variance (F1: $52.70 \%$; F2: $22.20 \%$ ). Hence, the first group was composed by the Oueslati fruit and pulps oils, known for their high levels of squalene, oxygenated monoterpenes and sesquiterpene hydrocarbons. The second one was characterized by the Chemlali variety whole fruit and pulps oils, owing to their medium contents of squalene, high levels of total alcohols, acceptable olive oil quality, with an equilibrated fatty acid profile. Finally, the third group was made up of four samples: Chemlali and Oueslati seed oils. This group known for their high levels unsaturated fatty acids. after the Varimax rotation (Fig. 2b), F1 was dominated by the following variables: Free fatty acids; Peroxide value; $\mathrm{K}_{232} ; \mathrm{K}_{270}$; chlorophylls; Carotenoids; 16:0; C16:1n-7; C17:0; C18:0; C18:1n-7; C18:3n-3; C20:0; C20:1n-9; C22:0; C24:0; Total aldehydes; Total alcohols; Total $\mathrm{C}_{6}$ aldehydes.

F2 was dominated by the following variables: C16:1n-9, C17:1n-8, C18:2n-6, C24:0, squalene, monoterpene hydrocarbons, oxygenated monoterpenes, sesquiterpene hydrocarbons, non-terpene derivatives, total $\mathrm{C}_{6}$ alcohols.

These results were confirmed by the Hierarchical Cluster analysis (HCA). In fact, Fig. 2c shows three distinct clusters based on the threshold value (equal to 0.864 ), with a high similarity between the seed oil samples, whereas the oils obtained from whole fruits and pulps of the two varieties presented an extreme dissimilarity in their composition both between them and in comparison to the variety. In this case, the formation of clusters and its linkage could be compared with and related to the groups formed in PCA (Fig. 2a).

In conclusion, the different parts of the olive (seeds, pulp and whole fruits) seem to play a very significant role in the qualitative characteristics and the sensory attributes of Chemlali and Oueslati olive oils. The application of SPME to the analysis of virgin olives oil headspace has allowed the detection of significant differences in the proportion of volatile constituents according to the different parts of the olives and the different cultivars. These results have proven that the cultivar and the olive parts influence the quali- 

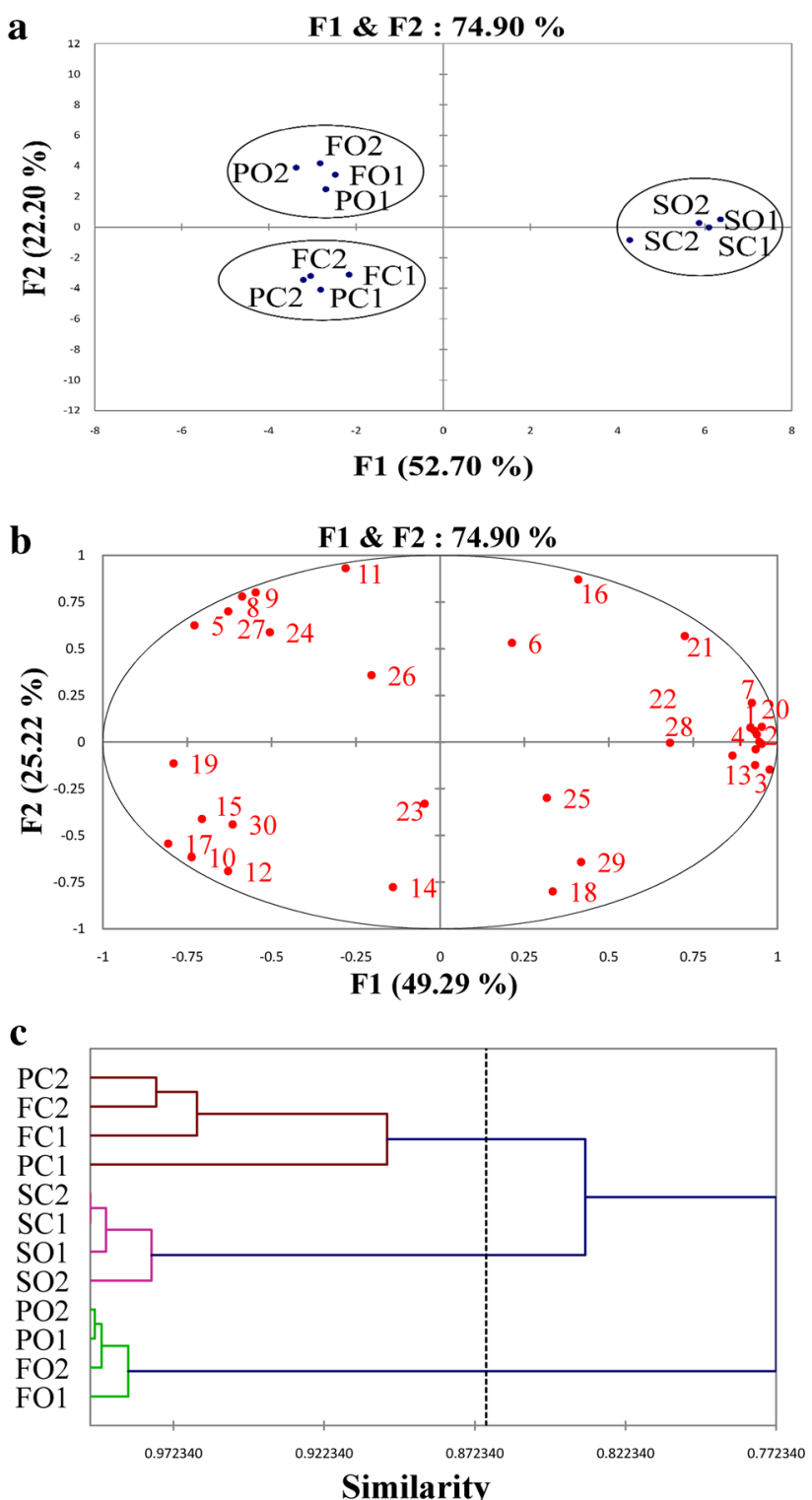

Figure 2. Chemometric analysis. (a): Principal component analysis (PCa) on F1 and F2 of the different parts (whole fruits, pulps, and seeds) of Chemlali and Oueslati oils. (b): Correlation loadings on $\mathrm{F} 1$ and $\mathrm{F} 2$ of 30 variables 1 : Free fatty acids; 2 : Peroxide value; 3: $\mathrm{K}_{232} ; 4$ : $\mathrm{K}_{270} ; 5$ : chlorophylls; 6:Carotenoids; 7: 16:0; 8: C16:1n-9; 9: C16:1n-7; 10: C17:0; 11: C17:1n-8; 12: C18:0; 13: C18:1n-9; 14: C18:1n-7; 15: C18:2n-6; 16: C18:3n-3; 17: C20:0; 18: C20:1n-9; 19: C22:0; 20: C24:0; 21: Squalene; 22: Monoterpene hydrocarbons; 23: Oxygenated monoterpenes; 24: Sesquiterpene hydrocarbons; 25: apocarotenoids; 26: Non-terpene derivatives; 27: Total aldehydes; 28: Total alcohols; 29: Total $\mathrm{C}_{6}$ aldehydes; 30: Total $\mathrm{C}_{6}$ alcohols.(c): $\mathrm{HCa}$ dendrogram showing clustering of the all the analyses performed on Chemlali and Oueslati virgin olive oils obtained from different parts of olive. quantitative production of volatiles and consequently the final aroma of the oil.

The authors would like to thank the Ministry of Higher Education and Scientific Research of Tunisia (Contrat programme LR14ES08), for their support of this research work. They also wish to extend their thanks to Mrs. Leila MAHFOUDHI, an English teacher at the Sfax Faculty of Science, for having proofread this paper.

The authors have declared no conflict of interest.

\section{References}

[1] DGPa/ O. N. H., L'oléiculture tunisienne. Olivae 1996, 61, 12-20.

[2] Trigui, A., Msallem, M., Yengui, A., Belguith, H., et al. Catalogue des variétés autochotones et types locaux. Ministère de l'agriculture, IRESA. Institut de l'Olivier 2002, 159p.

[3] Ryan, D., Robards, K., Lavee, S., Assessment of quality in olive oil. Olivae 1998, 72, 23-41.

[4] Issaoui, M., Flamini, G., Brahmi, F., Ben-Hassine, S., et al. Effect of the growing area conditions on differentiation between Chemlali and Chetoui olive oils. Food Chem. 2010, 1192, 220-225.

[5] Ouni, Y., Flamini, G., Ben, Y., Guerfel, N., Sterolic compositions and triacylglycerols of Oueslati virgin olive oil: Comparison among different geographic areas. Int. F. Food Sci. Technol. 2011, 46, 1747-1754.

[6] Del Caro, A., Vacca, V., Poiana, M., Fenu, P., Piga, A., Influence of technology, storage and exposure on components of extra virgin olive oil (Bosana cv) from whole and de -stoned fruits. Food Chem. 2006, 311-316.

[7] Flamini, G., Headspace analyses in valuable and functional foods: application of SPME in the quality control and characterization of olive oils. Current analytical Chemistry. 2007, 3, 149-159.

[8] Uceda, M., Frias, L., Evolution of the fruit oil content, oil composition and oil quality. In Proceedings of the del Segundo. Seminario Oleicola Internacional, COI, Cordoba. Spain. 1975, 125-128.

[9] International Organization for Standardization (2009), animal and vegetable fats and oils - Determination of acid value and acidity. ISO standard 660, International Organization for Standardization Geneva, Switzerland.

[10] International Organization for Standardization (2007), animal and vegetable fats and oils, Determination of peroxide value, Iodometric (visual) endpoint determination, ISO standard 3960, International Organization for Standardization Geneva, Switzerland.

[11] International Olive Council (IOC). (2013). Trade standard applying to olive oils and olive pomace oils. COI/T, 15/NC no 3 Rev 7. Principe de Vergara, 154, 28002, Madrid, Spain.

[12] Minguez Mosquera, M. I., Gandul Rojas, B., Montanoasquerino, A., Garrido-Fernandez, J., Determination of chlorophylls and carotenoids by HPLC during olive lactic fermentation. F. Chromatogr. 1991, 585, 259-266. 
[13] European Standard NF EN ISO 5509 Norm (2000). Preparation of methyl esters of fatty acids. AFNOR. Paris, France.

[14] European Standard NF EN ISO 5508 Norm (1995). Analysis by gas chromatography of methyl esters of fatty acids. AFNOR. Paris, France.

[15] Ollivier, D., Artaud, J., Pinatel, C., Durbec, J. P., Guérère, M., Triacylglycerol and Fatty acid Compositions of French Virgin Olive Oils Characterization by Chemometrics. F. agric. Food Chem. 2003, 51, 5723-5731.

[16] Flamini, E., Chericoni, G., Cremonini, S., Volatile compounds from three cultivars of Olea europea from Italy. $\mathcal{F}$. agric. Food. Chem. 2001, 49, 5409-5411.

[17] Adams, R. P. Identification of essential oil components by gas chromatography/mass Spectroscopy. Carol Stream, IL: Allured Publishing Company. 1995.

[18] Flamini, G., Cioni, P. L., Morelli, I., Volatiles from leaves, fruits, and virgin oil from Olea europaea cv. Olivastra Seggianese from Italy. F. agric. Food. Chem. 2003, 51, 1382-1386.

[19] Salvador, M. D., Aranda, F., Fregapane, G., Influence of ripening on Cornicabra virgin olive oil quality. a study of four successive crop seasons. Food Chem. 2001, 73, 45-53.

[20] Torres, M. M., Maestri, D. M., Chemical composition of arbequina virgin olive oil in relation to extraction and storage conditions. F. Sci. Food. Agric. 2006, 86, 2311-2317.

[21] Lazzez, A., Perri, E., Caravita, M. A., Khlif, M., Cossentini, M., Influence of olive maturity stage and geographical origin on some minor components in virgin olive oil of the Chemlali variety. F. Agric. Food Chem. 2008, 56, 982-988.

[22] Owen, R. W., Mier, W., Giacosa, A., Hull, W. E., Spiegelhalder, B., Phenolic compounds and squalene in olive oils: The concentration and antioxidant potential of total phenols, simple phenols, secoiridoids, lignans and squalene. Food Chem. Toxicol. 2000, 38, 647-659.

[23] Boskou, D, in: D. Boskou (Ed.), Other important minor constituents Olive oil. Minor constituents and health., Boca Raton, FL:CRC Press.2009 pp. 45-54.
[24] Fernandez, J. F., Lizzani-Cuvelier, X., Loiseau, L., Characterization of volatile compounds of french and spanish virgin olive oils by HS SPME: Identification of quality freshness markers. Food Chem. 2004, 88, 151-157.

[25] Angerosa, F., Influence of volatile compounds on virgin olive oil quality evaluated by analytical approaches and sensor panels. Eur. F. Lipid Sci. Technol. 2002, 104, 639660.

[26] Angerosa, F., D’alessandro, N., Basti, C., Vito, R., Biogeneration of volatile compounds in virgin olive oil: their evolution in relation to malaxation time. J. agric. Food. Chem . 1998, 46, 2940-2944.

[27] Allen, C. M., Bedgood, M. S., Prenzler, G., Robards, P. D., Olive oil volatile compounds, flavour development and quality: A critical review. Food Chem. 2007, 100, 273286.

[28] Sánchez, J., Salas, J. J., Biogenesis of the olive oil aroma, in: J. Harwood R. Aparicio (Eds.), Handbook of olive oil: Analysis and properties. Gaithersburg, MD, USA: Aspen, publication, Inc. 2000, 978, 4614-7776.

[29] Morales, M. T., Rios, J. J., Aparicio, R., Changes in the volatile composition of virgin olive oil during oxidation: Flavors and off-flavors. F. Agric. Food Chem. 1997, 45, 26662673.

[30] Mateos, R., Cert ,A., Pérez Camino, M. C., Garcia, M. J., Evaluation of virgin olive oil bitterness by quantification of secoiridoid derivatives.. F. Am. Oil Chem. Soc. 2004, 81, 71-75..

[31] Andrewes, P., Bush, J. L. H. C., De Joode, T., Groeneken, A., Alexandre, H., Sensory properties of virgin olive oil polyphenols: Identification of deacetoxy-ligstroside aglycon as a key contributor to pungency. F. Agric. Food Chem. 2003, $51,1415-1420$.

[32] Gargouri, B., ammar, S., Zribi, A., Ben Mansour, A., Bouaziz, M., Effect of growing region on quality characteristics and phenolic compounds of Chemlali extra-virgin olive oils. Acta Physiol Plant. 2013, 35, 2801-2812. 